\title{
Developmental pattern and regulation by androgens of androgen receptor expression in the urogenital tract of the rat
}

\author{
F.M. Bentvelsen*a, A.O. Brinkmann ${ }^{\text {a }}$, P. van der Schoot ${ }^{\mathrm{a}}$, J.E.T.M. van der Linden ${ }^{\mathrm{a}}$ \\ Th.H. van der Kwast ${ }^{b}$, W.J.A. Boersma ${ }^{c}$, F.H. Schröder ${ }^{a}$, J.M. Nijman ${ }^{\mathrm{a}}$ \\ ${ }^{2}$ Departments of Pediatric Urology, Endocrinology and Reproduction, Erasmus University and Academic Hospital, Rotterdam, The \\ Netherlands \\ bepartment of Pathology, Erasmus University and Academic Hospital, Rotterdam, The Netherlands \\ ${ }^{\mathrm{c}}$ T.N.O. Medical Biological Laboratory, Rijswijk, The Netherlands
}

Received 17 March 1995; revision received 22 May 1995; accepted 22 May 1995

\begin{abstract}
Distribution and regulation of androgen receptor expression during fetal and neonatal virilization of the rat fetus was assessed by immunohistochemistry. In mesonephric duct derivatives the androgen receptor expression became evident first in the efferent ductules and epididymis (on fetal day 14), subsequently in the vas deferens and finally in the seminal vesicle. Mesenchymal cells of the urogenital tubercle were positive for androgen receptors from fetal day 14 onwards. In the mesenchymal cells of the prostate anlagen, androgen receptor positive cells were found first on fetal day 16. Administration of $5 \alpha$-dihydrotestosterone to pregnant rats from day 11 to day 20 of gestation caused a stabilization of the wolffian duct in female fetuses. The androgen receptor expression pattern became similar as found in male fetuses, and showed an increase in density and in frequency of androgen receptor positive cells. Administration of the androgen antagonist flutamide during the same interval caused a reduction in density and frequency of androgen receptor positive cells in male fetuses. These findings indicate that androgens enhance the expression of androgen receptors in the developing rat genital tract by induction of androgen receptor positive cells, and by increasing the frequency. The developmental pattern of androgen receptor expression in the rat mesonephric duct system reflects the androgen-responsiveness of the ducts, and is consistent with induction of the androgen receptor along the ducts by testosterone reaching these structures in an exocrine fashion.
\end{abstract}

Keywords: Receptor; Androgen; Fetus; Rat

\section{Introduction}

Normal development and functioning of male genitalia are primarily controlled by androgens (Wilson et al., 1981). In most androgen target cells testosterone is converted into its metabolite $5 \alpha$-dihydrotestosterone. Testosterone and $5 \alpha$-dihydrotestosterone play separate roles in fetal male differentiation: testosterone mediates wolffian duct virilization, while differentiation of the urogenital sinus and

\footnotetext{
* Department of Pediatric Urology, Sophia Children's Hospital, Dr. Molewaterplein 60,3015 GJ Rotterdam. The Netherlands.
}

the external genitalia depends upon $5 \alpha$-dihydrotestosterone (Griffin and Wilson, 1989). The different roles of the two hormones is clearly reflected in the $5 \alpha$-reductase type 2 deficiency syndrome. In individuals with this syndrome masculinization of the urogenital sinus and external genitalia does not occur during fetal life, but wolffian duct development proceeds into epididymis, vas deferens and seminal vesicle. Compelling evidence exists that both testosterone and $5 \alpha$-dihydrotestosterone act via the same receptor protein, because in individuals with the complete form of androgen insensitivity the wolffian duct stabilization, as well as virilization of the urogenital sinus and tubercle, are affected (Griffin and Wilson, 1989). 
Differentiation of the wolffian ducts into male internal genitalia begins at week 8 of gestation in man, and at fetal day 14 in the rat (Price and Ortiz, 1965). During early development of male genitalia the distribution of AR differs from that of later stages in that AR expression initially is present only in mesenchymal cells and later also appears in the epithelium (Cooke et al., 1991). Androgens induce epithelial differentiation of the genitalia via action in mesenchymal cells (Shannon and Cunha, 1983; Takeda et al., 1985).

In earlier work we have demonstrated that during early sexual differentiation in the male and female rat fetus ARs are present at equally high levels in the urogenital tubercle and sinus of both sexes (Bentvelsen et al., 1994). In the tubercle of male fetuses AR expression increases with time, while in female fetuses AR protein expression of the tubercle diminishes. Those immunoblotting studies, however, were by no means conclusive with respect to the cellular distribution of the AR, either these changes are caused by alterations in the cellular density of AR expression or in the frequency of AR positive cells. Studies on the cellular distribution of AR expression in the developing urogenital tract are based on autoradiography (Shannon and Cunha, 1983; Takeda et al., 1985; Cooke et al., 1991). In autoradiographic studies, however, radioactivity is detected, not only of the primary label, but also including the metabolites of androgens that might have binding characteristics different from the primary label. In the cells which are negative in the autoradiograms, occupancy of the $\mathrm{AR}$ by endogenous unlabelled ligand cannot be excluded. This consequently results in a false negative signal.

Since a sensitive specific immunohistochemical assay for paraffin-cmbedded tissues was developed recently (Janssen et al., 1994), we have used this assay to re-examine the developmental pattern of the differential expression of the AR at the protein level. Our observations indicate that androgens enhance the expression of $A R$ in developing rat genital tract by increasing the density and frequency of AR positive cells.

\section{Materials and methods}

\subsection{Animals}

Wistar rats (obtained from TNO, Rijswijk, The Netherlands) were maintained under controlled conditions of day and night (14 and $10 \mathrm{~h}$, respectively) and temperature $\left(20 \pm 1^{\circ} \mathrm{C}\right)$ and allowed free access to standard laboratory chow and tap water. Timed pregnant dams (vaginal plug $=$ day 0 ; term $=$ day 22) were killed at the start of sexual differentiation of the mesonephric ducts on day 14 , and further on days
$16,18,20$ and 21 of pregnancy. Fetuses were removed immediately. Newborn rats were sacrificed on days 2 , 5 and 10. Flutamide (a kind gift from Schering Corp., Bloomfield, NJ) was administrated $100 \mathrm{mg} / \mathrm{kg}$ body weight per day, and $5 \alpha$-dihydrotestosterone (DHT) 50 $\mathrm{mg} / \mathrm{kg}$ body weight per day. Both drugs were dissolved in $10 \%$ ethanol $/ 90 \%$ olive oil and were administered daily by subcutaneous injection from day 11 to day 20 of gestation. The treated fetuses were killed on day 21 .

Fetuses and neonates were fixed in $10 \%$ neutral phosphate-buffered formalin. After $24 \mathrm{~h}$ the bodies were cut into two halves. Sex was confirmed by gonadal inspection. From each age, two to four animals were analyzed. The lower body halves (without intestines, extremities and tail) were embedded in paraffin.

\subsection{Antiserum against $A R$}

The antiserum used was raised in rabbits against a synthetic peptide identical to the first 20 amino acid residues of the $\mathrm{N}$-terminal domain of the human and rat AR. The polyclonal antibodies were developed as previously described (Zegers et al., 1991). The oligopeptides were conjugated to keyhole limpet hemocyanin (KLH, Calbiochem, San Diego, CA) for immunization of rabbits (Flemish Giant random bred, MBL-TNO, Rijswijk, The Netherlands). The sera were tested in a direct ELISA for antipeptide response, and in an immunoprecipitation assay for AR specificity. The antibodies will be referred to as SP197 (Janssen et al., in preparation).

\subsection{Immunohistochemistry}

Details for immunohistochemical procedures have been reported previously (Janssen et al., 1994). All sections $(5 \mu \mathrm{m})$ were cut transversely and mounted on slides coated with 3-aminopropyl triethoxy-silane (Sigma Chemical Co., S. Louis, MO). Slides were dried overnight at $60^{\circ} \mathrm{C}$, dewaxed and rehydrated, after endogenous peroxidase activity was blocked with $3 \% \mathrm{H}_{2} \mathrm{O}_{2}$ in methanol. Sections were then microwaved three times for $5 \mathrm{~min}$ at $700 \mathrm{~W}$ under 0.01 $\mathrm{M}$ citric acid monohydrate buffer ( $\mathrm{pH}$ 6.0), after which they were cooled to room temperature and rinsed with PBS ( $\mathrm{pH}$ 7.4). The sections were pre-incubated with $10 \%$ normal goat serum (Dako, Glostrup, Denmark) in PBS for $15 \mathrm{~min}$. Then sections were incubated overnight at $4^{\circ} \mathrm{C}$ with the primary antibodies SP197. The immune serum SP197 was diluted 1:8000 in PBS (vol/vol). Control sections were incubated either with nonimmune rabbit serum, diluted to the same extent as the primary antibodies, or with the primary antibodies, after incubation of the antibodies overnight with an excess of the free peptide $(1 \mathrm{mg} / \mathrm{ml})$, which was used to raise the antibodies. The anti- 
bodies and peptide were diluted to $1: 8000$ in PBS (vol/vol) for blocking experiments. Staining was carried out by the avidin-biotin peroxidase method. Cells were considered AR positive, when a nuclear staining was observed. Nuclear counterstaining was performed with Mayer's hematoxylin.

\section{Results}

\subsection{Immunohistochemistry}

Efferent ductules. Day 14 is the onset of sexual differentiation of the efferent ductules and wolffian duct in the rat fetus. The efferent ductules contained some AR + mesenchymal cells on day 14 (Fig. 1a). At this age the efferent ductules were the first sites of the mesonephric duct system in which AR expression also occurred in epithelial cells. Preincubation of the antibodies with the corresponding peptide blocked the nuclear staining pattern (Fig. 1c). During the whole further period of gestation from day 14 to day 10 after birth both epithelium and mesenchyme of the efferent ductules were AR + .

Wolffian duct. The mesenchyme around the wolffian duct exhibited nuclear staining on day 14 (Fig. $1 a, b)$. At the medial side of the wolffian duct more mesenchymal cells showed AR + than at the lateral side, close to the müllerian duct $(n=4)$. The epithelia of the wolffian duct and the müllerian duct were negative at days 14 and 16 . At day 18 of gestation, epithelial cells of the epididymal head stained for AR (Fig. 1d). The epididymal tail showed mesenchymal cells expressing the AR from day 18 of gestation (Fig. 1e), but epithelium remained negative. Epithelial cells of the epididymal tail were weakly AR + at day 2 after birth. At days 5 and 10 the proportion of epithelial AR + cells was increased (Fig. 1f) as compared to day 2 .

In the vas deferens (distal wolffian duct) the AR was not detectable on days 14,16 and 18 , but became weakly detectable in the mesenchyme on fetal day 20 and in the epithelium from day 2 postnatally. On day 5 , the epithelium of the vas deferens contained exclusively positive cells surrounded by a ring of AR-negative tissue: the basal cell layer (Fig. 1f). This basal cell layer was surrounded by a ring of AR + mesenchymal cells. The seminal vesicles exhibited AR + cells in the mesenchyme from fetal day 21 onwards, and in the epithelium from day 2 after birth (Fig. 2c).

Urogenital sinus. On fetal day 14 the prostate anlagen did not show the AR, but some staining of cells in the urothelium on top of the verumontanum was found, at the site where the ejaculatory ducts enter the sinus (Fig. 2a). On fetal day $16 \mathrm{AR}+$ cells were found only in the mesenchymal part of the prostate anlagen. The mesenchyme of the prostate stained intensively at fetal day 18 (Fig. 2b). At this stage, a higher frequency of cells of the urothelium expressing the AR was observed. On day 2 a few epithelial cells of the prostate showed weak AR staining. The majority of epithelial cells of the prostate was AR + on day 5 after birth (Fig. 2c).

Urogenital tubercle, folds and swellings. The mesenchymal cells of the urogenital tubercle. of the genital folds and of the genital swellings, respectively, were positive for AR from fetal day 14 onwards (Fig. 2d). During development of the external genitalia the amount of mesenchymal cells expressing the AR increased progressively (Fig. 2e,f). The epithelial cells in the skin of the tubercle showed AR expression from day 5 after birth.

\subsection{Differential AR expression pattern in the urogenital tract compared with some other androgen-dependent developmental structures: mammary gland, gubernaculum and perineum}

Nipple primordia of mammary gland. In the nipple anlagen of the mammary gland many $\mathrm{AR}+$ mesenchymal cells were found on fetal day 14 (Fig. 3a).

Gubernaculum. At fetal day 18 , the mesenchyme of the gubernacular cone showed AR + cells, particularly in the core (Fig. 3b). Some positive cells were identified in the gubernacular ligament or cord (Figs. $3 \mathrm{~b}$ and $1 \mathrm{e}$ ).

Perineum and prepubic region. An abundant amount of mesenchymal AR + cells was noticed in the perineum from day 18 onwards (3c), and also in the prepubic region (not shown).

Female urogenital tissues. Müllerian duct structures remained negative for $\mathrm{AR}$ at all examined ages in male and female fetuses. In female fetuses at fetal days 18 and 21, AR expression in the regressing wolffian duct (Fig. 3d), urogenital sinus (Fig. 3e) and tubercle (Fig. 3f), respectively, was low compared to frequencies of $A R+$ cells observed in male fetuses.

\subsection{Effect of DHT or flutamide on AR expression in} genital tracts of female and male rat fetuses, respectively

Wolffian duct. Administration of $5 \alpha$-dihydrotestosterone from days 11 to 20 of gestation to pregnant rats caused a stabilization of the wolffian duct in female fetuses with an androgen receptor expression pattern similar to that found in male fetuses (Fig. 4a).

No AR was detectable in the mesenchyme around the wolffian duct from the male fetus on fetal day 21 , after exposure to flutamide given daily starting from fetal day 11 (Fig. 4b).

Urogenital sinus. High AR levels in the mesenchyme of the prostate anlagen in female fetuses after DHT were consistent with a masculine pattern of differentiation of the prostate anlagen (Fig. 4c). 
In the flutamide-treated male fetus, AR expression was diminished and prostate development was retarded (Fig. 4d).

Urogenital tubercle. In the female fetus, DHT administration caused an outgrowth of the tubercle which differentiated into the male direction, and an increase in cells positive for AR (Fig. 4e).

Administration of the androgen antagonist flu-

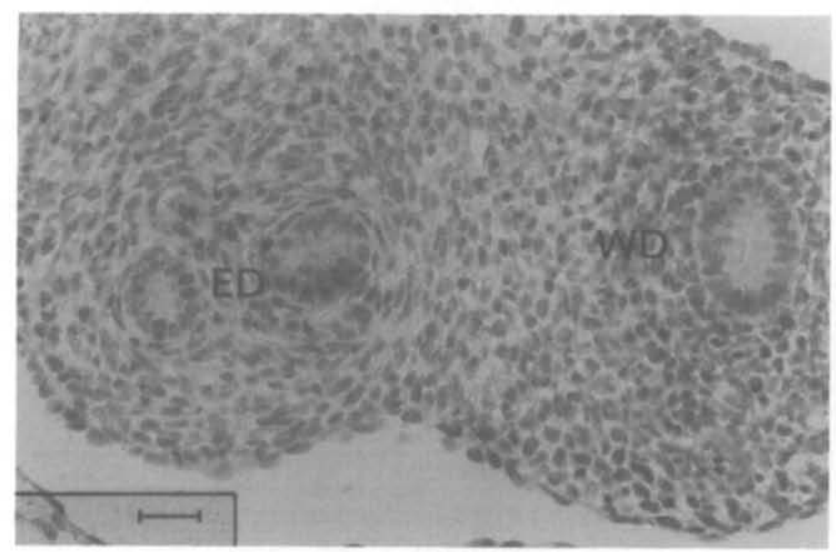

a

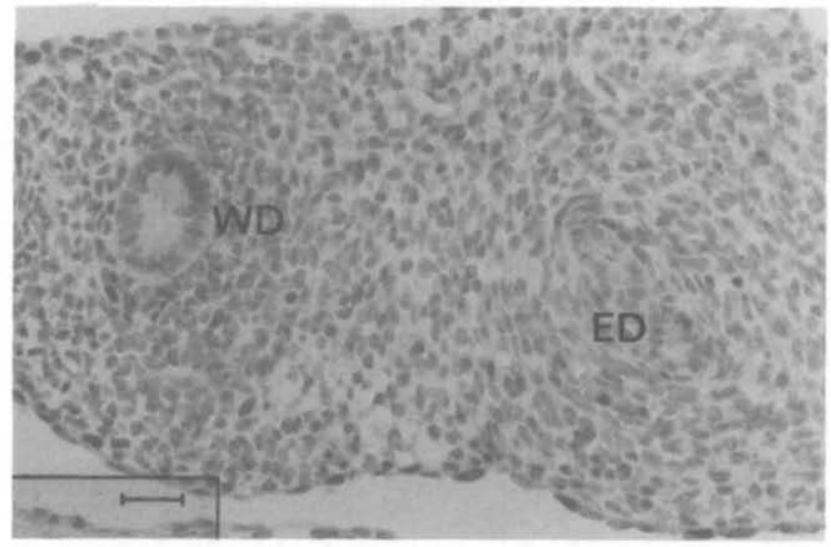

C

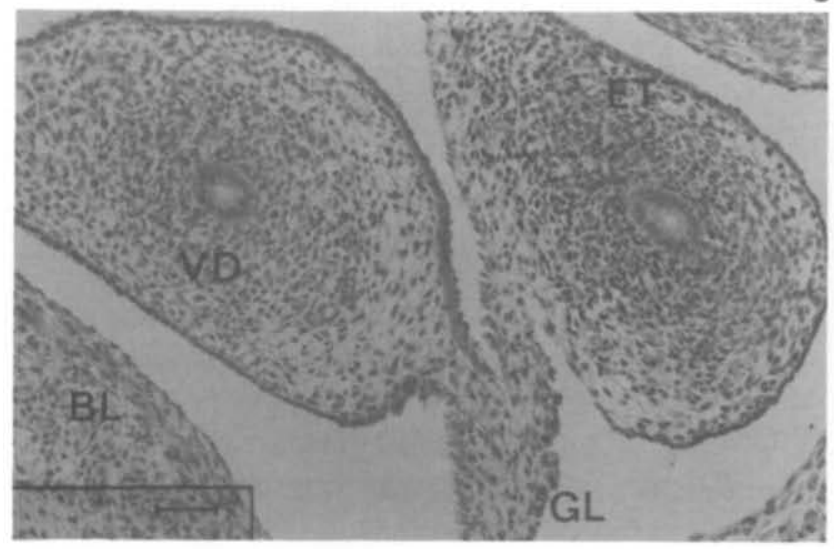

tamide in male fetuses caused a reduction in AR + cells and an underdevelopment of the urogenital tubercle with a wide open urethra (Fig. 4f).

\section{Discussion}

This study provides in vivo evidence that expression of the androgen receptor (AR) is regulated by andro-

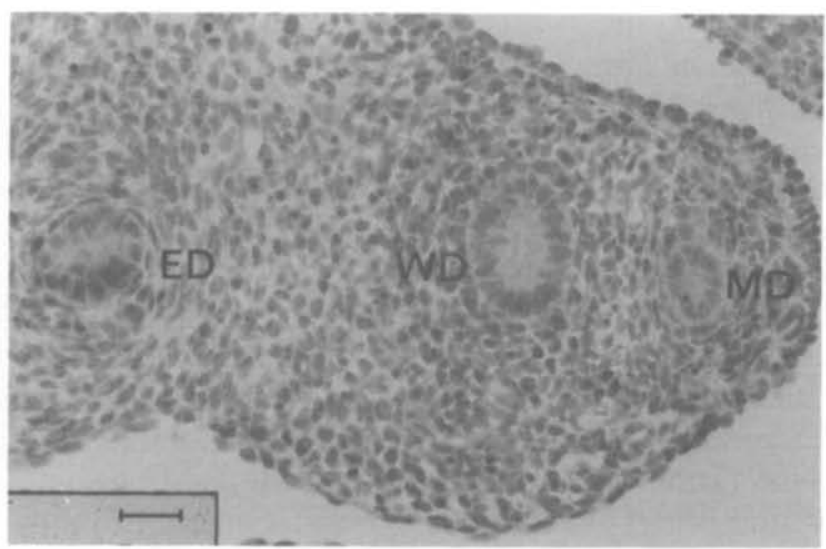

b

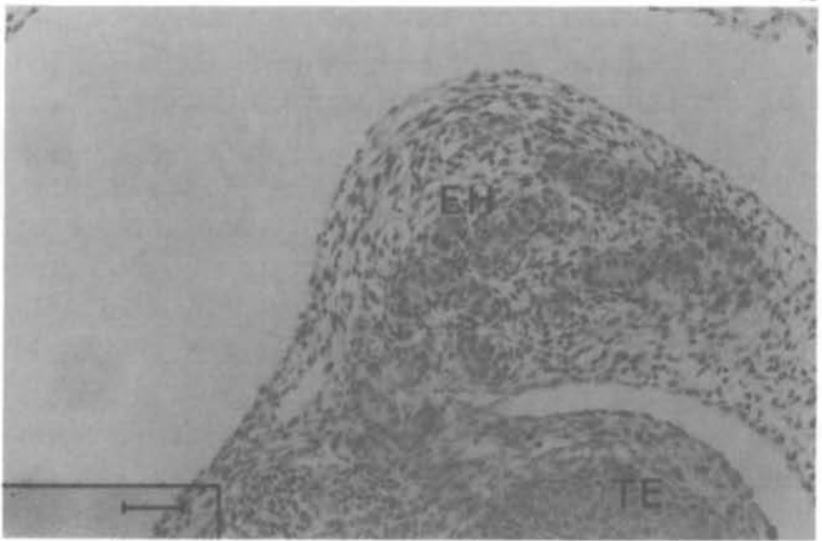

d

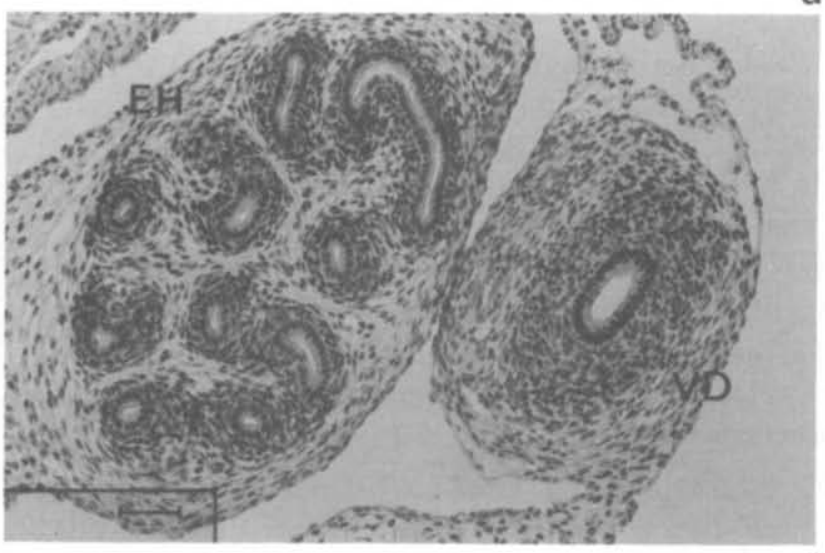

e

Fig. 1. Immunohistochemical staining of the androgen receptor in the wolffian duct. (a,b,c) Wolffian duct (WD), efferent ductules (ED) and müllerian duct (MD) are shown at fetal day 14. (c) The specificity of the immunoreactivity was indicated by the lack of nuclear staining after preincubation of the antibodies with the peptide SP197. (d) The epididymal head (EH) at fetal day 18, TE is testis. (e) The epididymis tail (ET) and the gubernacular ligament (GL), the vas deferens (VD) and the bladder (BI) at day 18. (f) The vas deferens and epididymal tail (neonatal day 5). Bar $=25 \mu \mathrm{m}$ in a,b,c; bar $=50 \mu \mathrm{m}$ in d,e,f. 

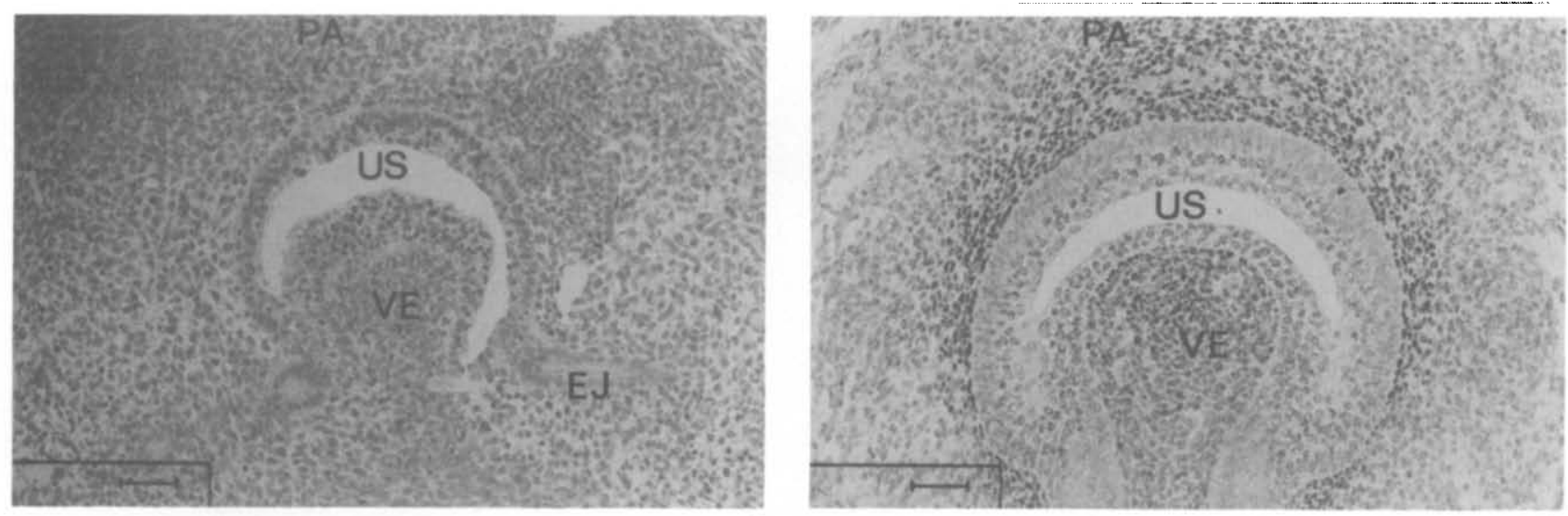

a
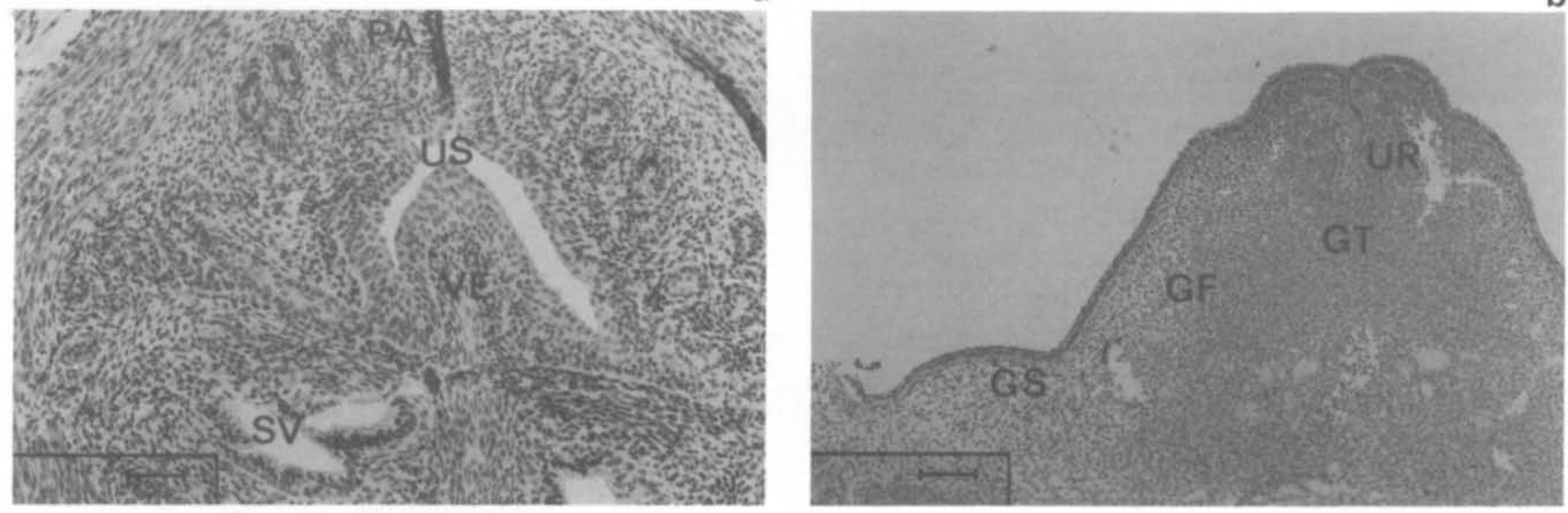

C
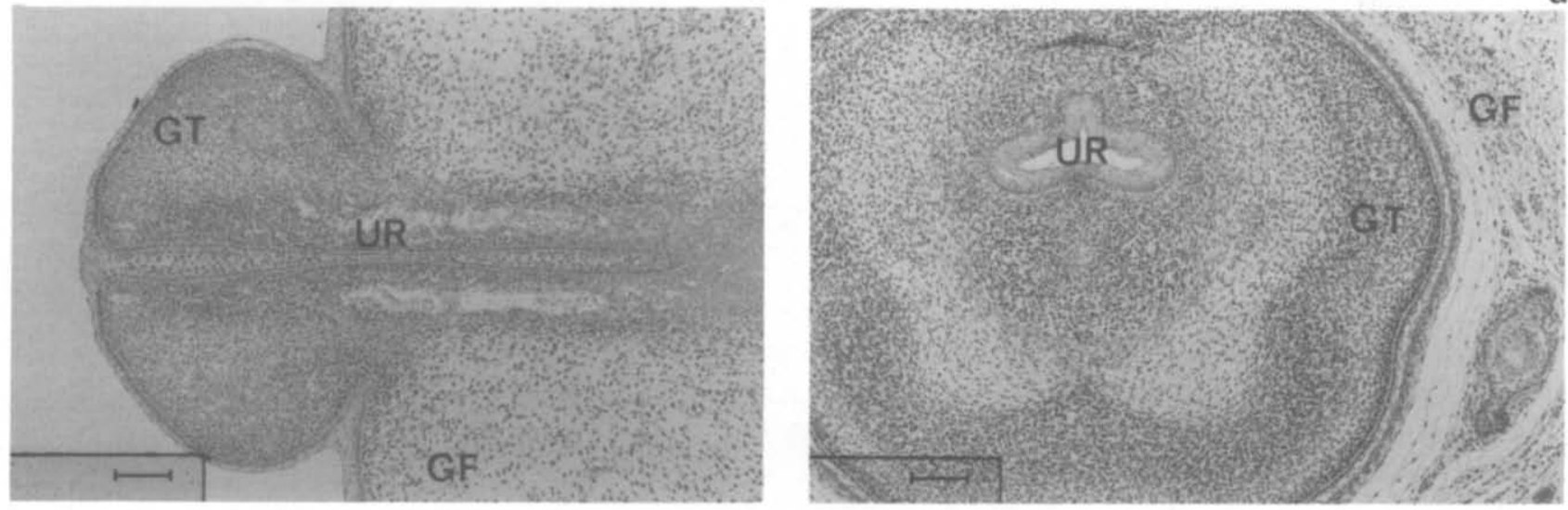

e

Fig. 2. Immunohistochemical staining of the androgen receptor in the genital tubercle, sinus and surrounding tissues in the male rat. (a) The urogenital sinus (US), the prostate anlagen (PA) and the verumontanum (VE) on fetal day 14 at the location, where the ejaculatory ducts (EJ) enter the sinus. (b) fetal day 18. (c) Budding of the prostate at postnatal day 5; SV are seminal vesicles. (d,e,f) The urogenital tubercle (GT) with urethra (UR), genital fold (GF) and swelling (GS). (d) day 14; (e) day 18; (f) 2 days after birth. Bar $=50 \mu \mathrm{m}$ in a,b,c; bar $=100 \mu \mathrm{m}$ in d,e,f.

gens during morphogenesis of the genitalia. The AR is first induced in the mesenchymal cells and subsequently in the epithelial cells. The sequential appearance of the AR in mesenchymal and in epithelial cells in fetal and neonatal male reproductive tissues is given in a timetable (Table 1). At fetal day 14 (the first day of investigation) only the efferent ductules showed some AR-positive epithelial cells as well as AR-positive mesenchymal cells. In other tissues, we found AR expression in the mesenchyme before the epithelium became positive.

From studies of the $5 \alpha$-reductase type 2 deficiency syndrome (Wilson et al., 1981) it is clear that the efferent ductules and the wolffian duct are stabilized 


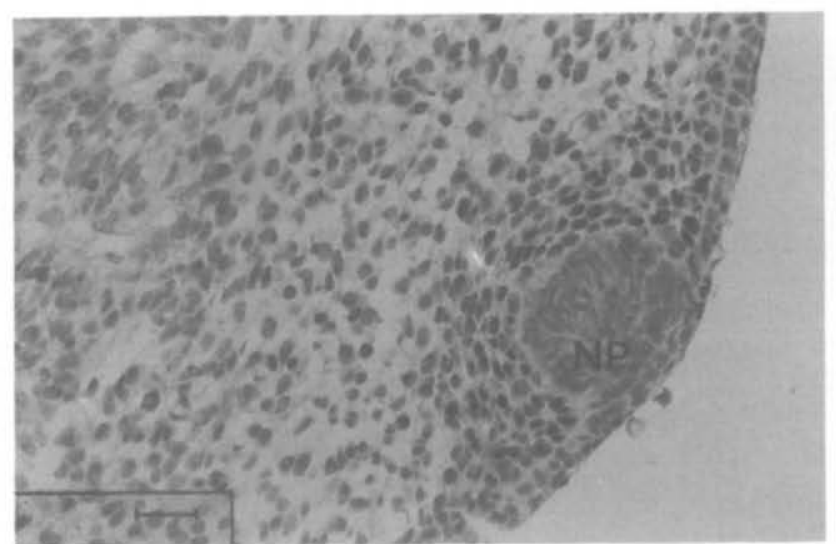

a

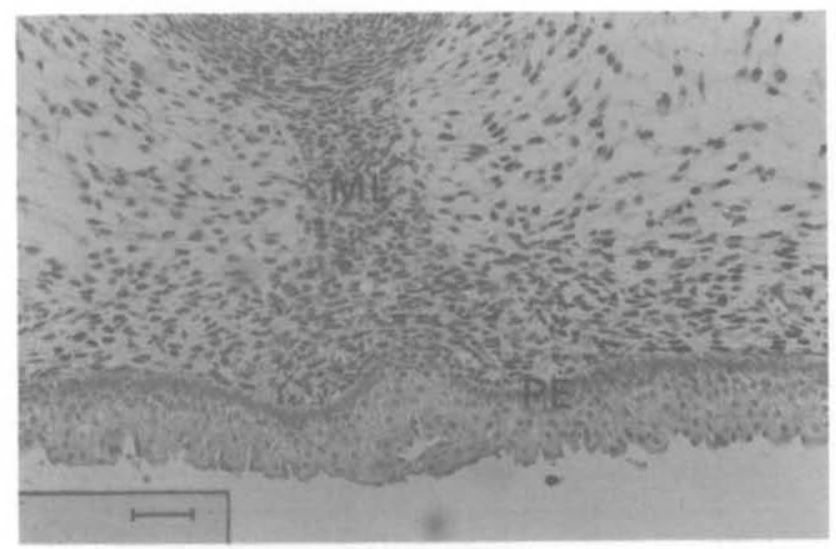

C

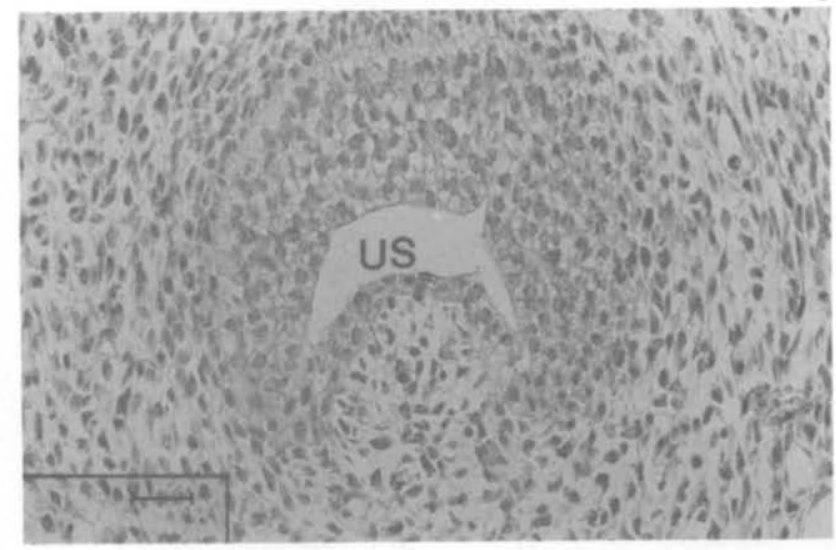

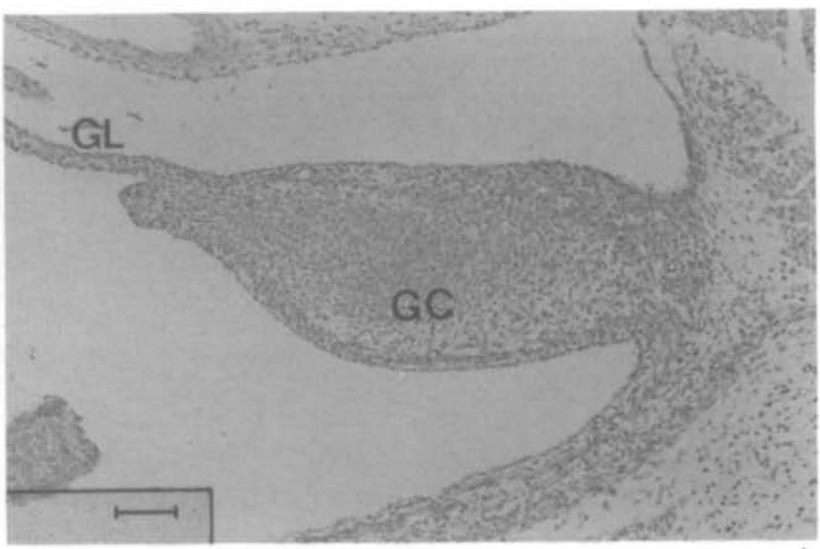

b

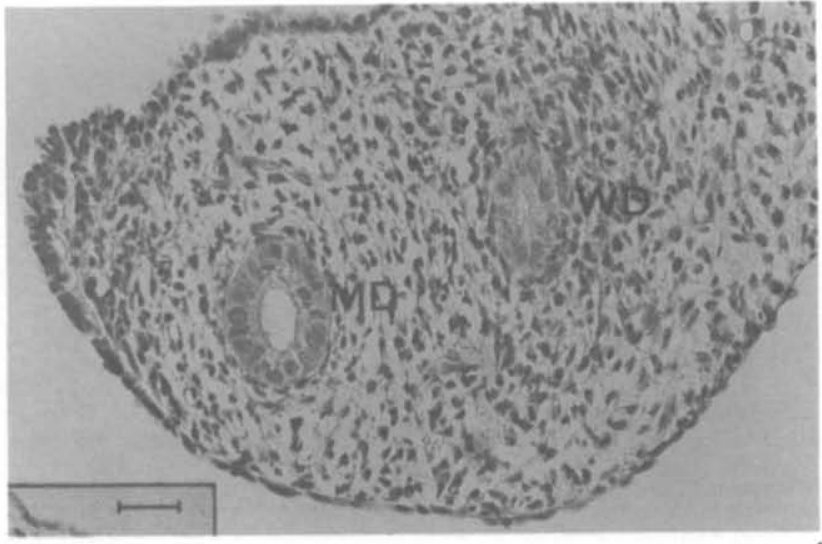

d

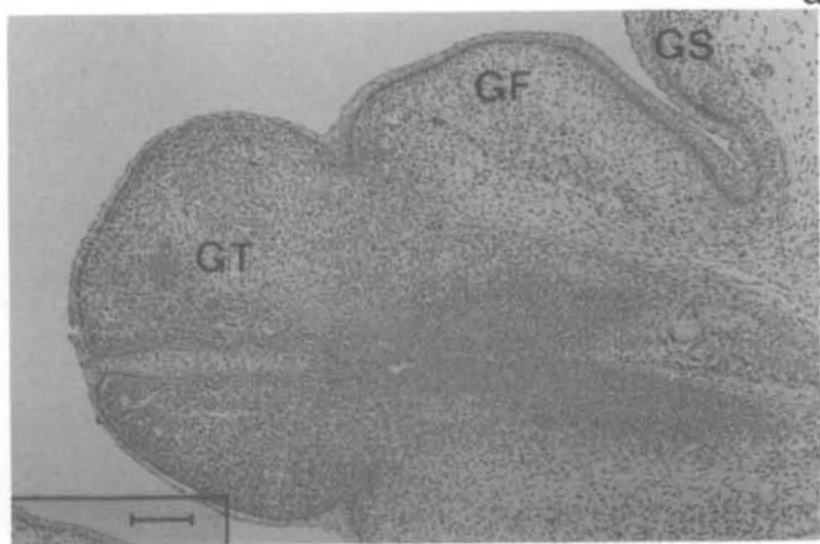

e

Fig. 3. Immunohistochemical staining of the androgen receptor in the nipple anlagen, in the gubernaculum and in the perineum of the male fetus, and in the müllerian and wolffian ducts, in the genital sinus and in the tubercle of the female fetus. (a) Day 14: the nipple anlagen (NP). (b) Day 18): the gubernacular cone (GC) and part of the ligament (GL). (c) Perineum (PE) at fetal day 18. The midline (ML) between the urethra and the skin is indicated. (d) Day 18: the mülterian duct (MD), the wolffian duct (WD) regresses. (e) Day 18: the female urogenital sinus. (f) Day 18: the female urogenital tubercle (GT), genital fold (GF) and swelling (GS). Bar $=25 \mu \mathrm{m}$ in a,d,e; bar $=50 \mu \mathrm{m}$ in c; bar $=$ $100 \mu \mathrm{m}$ in $\mathrm{b}, \mathrm{f}$.

by testosterone. Probably, testosterone interacts with these tissues in an 'exocrine' fashion: high concentrations of testosterone diffuse from the testis via the efferent ductules down the lumen of the wolffian duct, creating a testosterone gradient along the wolffian duct (Veyssiére, 1982). This concept is supported by a recent study in which transport of fluorescence- labelled testosterone down the wolffian duct was reported during sexual differentiation of the mouse (Tong and Hutson, 1994).

Since testosterone (and not $5 \alpha$-dihydrotestosterone) virilizes efferent ductules and wolffian duct, it is conceivable that tcstostcrone stabilizes the efferent ductules and the upper part the epididymis, 


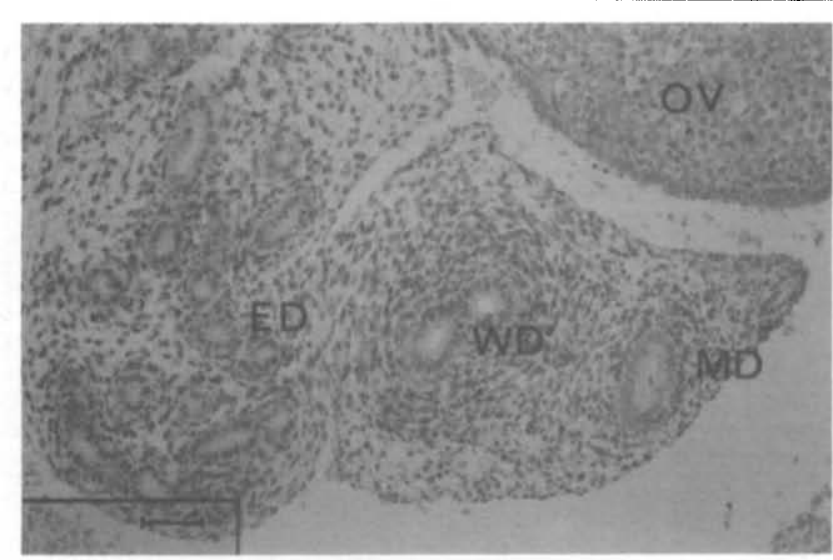

a

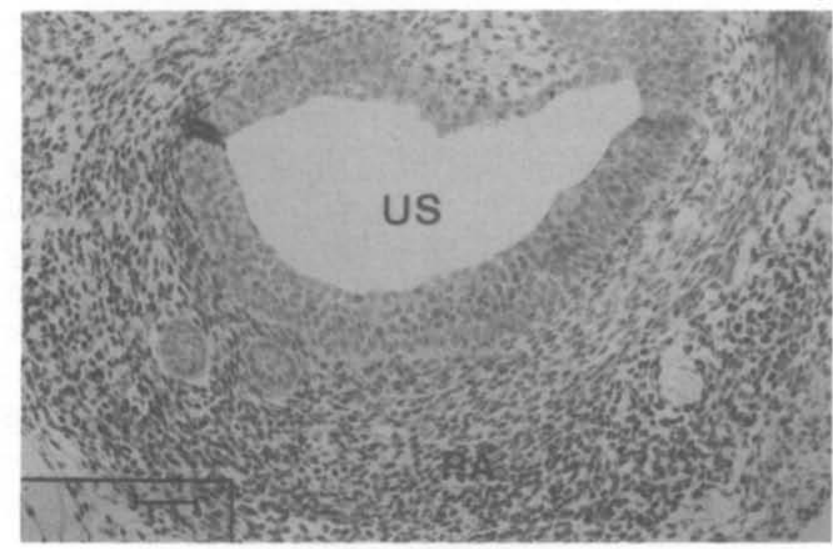

C

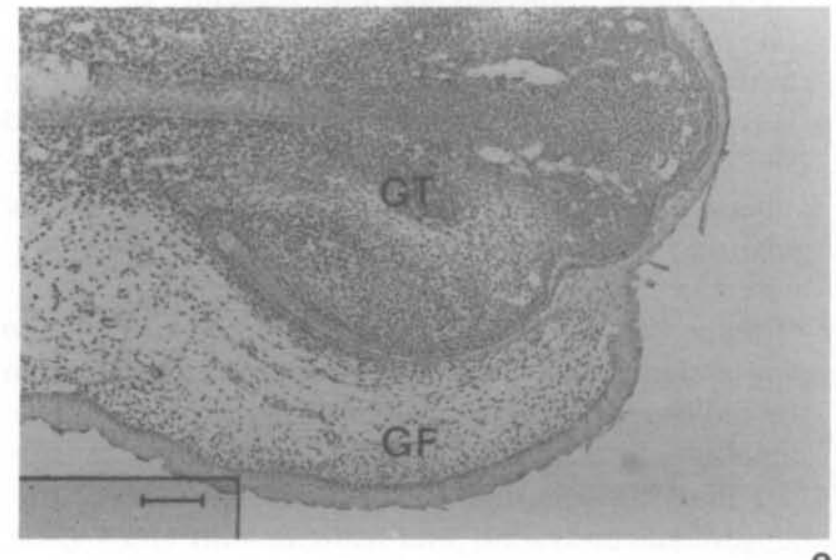

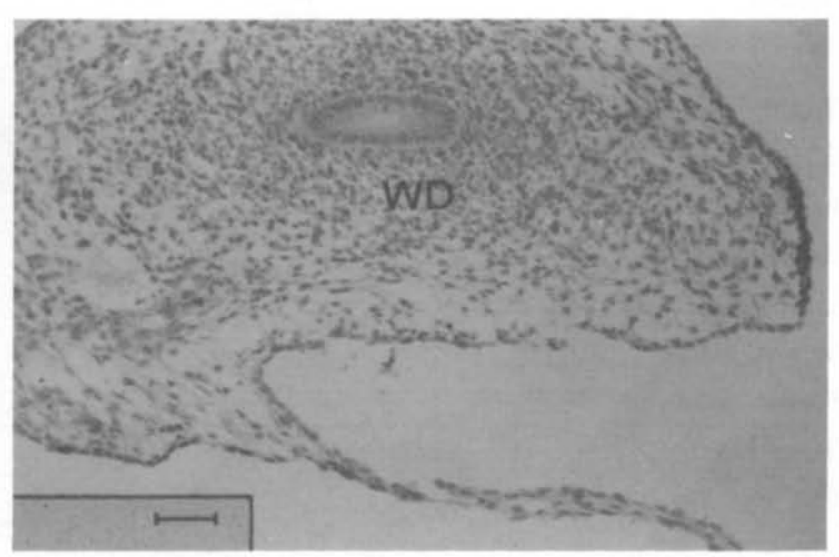

b

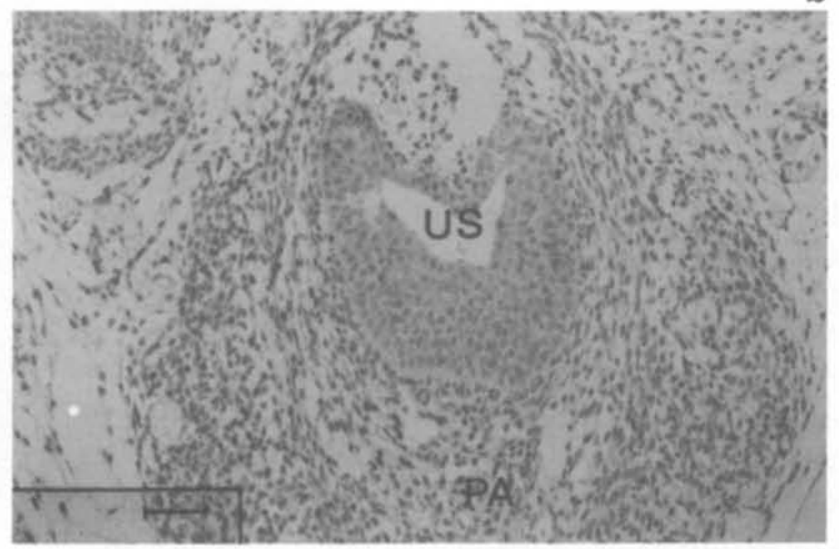

d

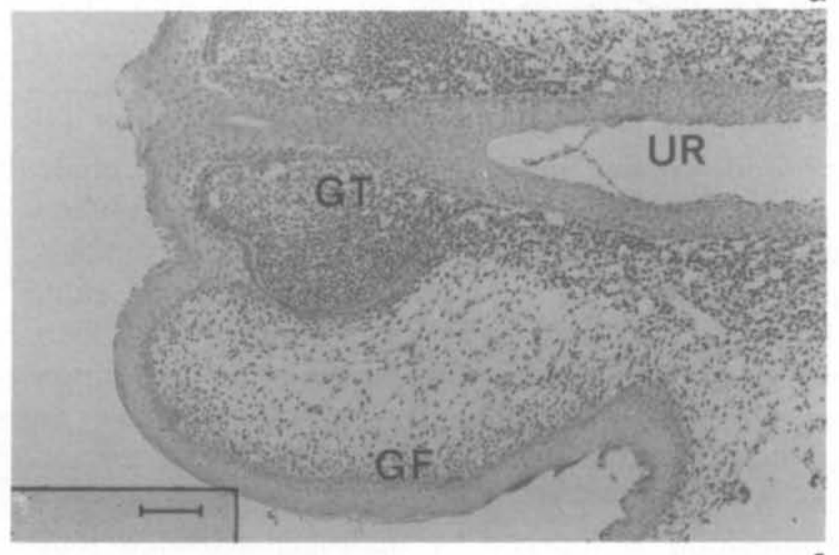

f

Fig. 4. Effect of $5 \alpha$-dihydrotestosterone on the urogenital tract in the female rat on fetal day 21 , and the effect of the anti-androgen flutamide on the genitalia in the male fetus of the same age. (a) Wolffian duct (WD) and the efferent ductules (ED) were present in the female (MD: müllerian duct, OV: ovary). (b) Wolffian duct after exposure to flutamide in the male. (c) Prostate anlagen (PA) ventral of the urogenital sinus (US) in the female fetuses treated with DHT. (d) Differentiation of the prostate anlagen (PA) was retarded in the flutamide treated male fetuses. (e) The virilized female genital tubercle (GT) and genital fold (GF). (f) Underdevelopment of the male genital tubercle with a clcft urethra (UR). Bar $=50 \mu \mathrm{m}$ in a,b,c,d; bar $=100 \mu \mathrm{m}$ in e,f.

followed by the remaining part of the epididymis, the vas deferens and finally the seminal vesicle. In some species, however, the distal part and, to a smaller extent, the middle part of the wolffian duct may be less dependent on virilization by testosterone (Tsju et al., 1994). Relatively high levels of testosterone reach these tissues by diffusion through the lumen of the mesonephric duct system, increasing AR expression in the efferent ductules and the medial side of the wolffian duct close to the testis, respectively, followed by the remaining part of the wolffian duct: the epididymis and, later in fetal life, the vas deferens and seminal vesicle. The higher content of androgen receptor observed at the medial part of the wolffian 
Table 1

AR expression in mesenchymal and epithelial cells during development of fetal and neonatal male genitalia.

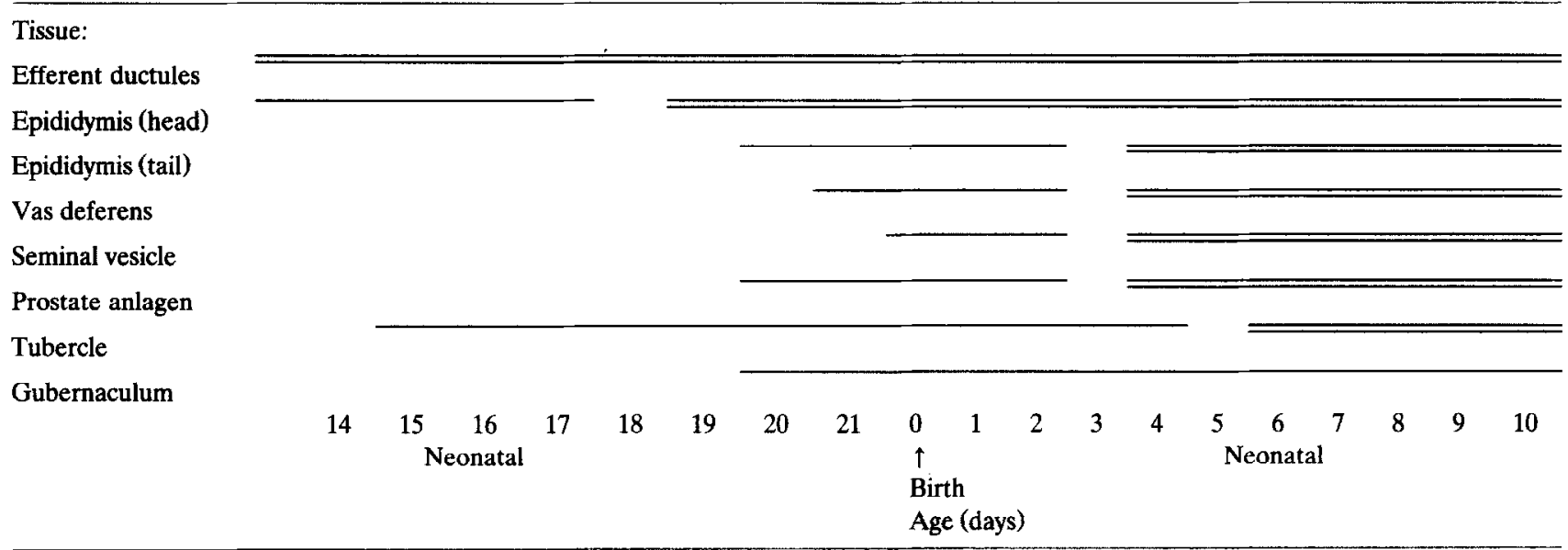

mesenchyme AR + (-); both mesenchyme and epithelium $\mathrm{AR}+(=)$.

duct in comparison to the lateral side may reflect a higher testosterone gradient caused by the hormonal diffusion from the testis. Prevention of transport of testosterone through the mesonephric duct derivatives may affect AR expression in the target cells negatively. Consequently androgen-dependent development may be inhibited, which results in degeneration of the vas deferens. According to this hypothesis, mechanical obstruction of hormonal transport in the epididymis could explain the congenital absence of the vas deferens as found in patients with cystic fibrosis (Tizzano et al., 1994).

Various modulating physiological effects of androgens during embryogenesis are mediated by AR expressed in the mesenchymal cells. For example, male-type differential growth of the urogenital tubercle stimulated by androgen action starts with an abundant AR-positive mesenchyme (Shannon and Cunha, 1983; Takeda et al., 1985; Husmann et al., 1990), while the effect of androgen action in the nipple primordia of the mammary gland in the male rat implies the ultimate regression of the nipple primordia (Wasner et al., 1983). The androgen-induced elimination is induced by androgen-activated mesenchymal cells, since the mesenchyme contained many AR-positive cells in contrast to the negative epithelium.

During the investigated period, the genital tubercle showed an increasing proportion of cells expressing $\mathrm{AR}$ in the mesenchymal cells. Five days postnatally, AR-expressing epithelial cells were noticed in the prepuce. The AR expression of the rat penis during maturation has been studied extensively previously (Gonzales-Cadavid et al., 1991; Takane et al., 1991). After sexual maturation, AR staining is only present in epithelial nuclei of preputial skin and urethra.

The presence of large amounts of $A R$ in the perineum suggests a role for androgens in perineal outgrowth. During sexual differentiation the rat penis migrates to a more ventral position than the female tubercle. George (1989) showed, that exposure of male rat fetuses to a $5 \alpha$-reductase inhibitor during sexual differentiation reduced the distance between the anus and tubercle, indicating that this process is highly $5 \alpha$-dihydrotestosterone dependent. Furthermore, in this caudal region in the rat, androgen action is reflected in the sexual dimorphism in the levator ani/bulbocavernosus muscle group (Jung and Baulieu, 1972).

The role of androgen action in testicular descent is still under debate (Van der Schoot, 1992). Our study confirms the presence of AR in the rat gubernaculum (Husmann and McPhaul, 1991; Bentvelsen and George, 1993). AR-pusitive cells are present in the gubernacular cord (or ligament) and in the core of the gubernacular cone, before inversion of the cone into a cremaster sac.

In the female genital tract AR does not seem to play a significant role. The protein disappears when the indifferent scxual stage has changed into a female direction. These data coincide with the observation that the critical period of $\mathrm{AR}$ action on the developing genitalia ends soon after birth (Schultz and Wilson, 1974). The decrease in the amount of AR-positive cells in female fetuses could be prevented by administration of DHT to the pregnant dams. Exposure to androgen caused a stabilization of the wolffian duct in the females. Furthermore, a decrease in the number of AR-containing cells in the genital tract of male fetuses was seen following the administration of the anti-androgen flutamide to pregnant rats.

In conclusion, these findings demonstrate the AR distribution in various tissues of the developing male genital tract of the male rat. Our data provide support for a mechanism by which androgens modulate the expression of $A R$ in the genital tract by induction and subsequently proliferation of AR-containing cells. It is consistent with the idea that virilization of the 
efferent ducts and the wolffian duct is accomplished by large amounts of testosterone reaching these structures in an exocrine fashion. In these tissues, testosterone induces the AR, first in the mesenchyme, and subsequently in the epithelium in a temporal fashion. The earliest expression is found in tissues with the smallest distance to the testis. In tissues virilized by $5 \alpha$-dihydrotestosterone in an endocrine way, ARs appear later, but also first in the mesenchymal cells, and thereafter in the epithelial cells. The factors in the mesenchyme mediating the epithelial induction of ARs remain to be determined.

\section{References}

Bentvelsen, F.M. and George, F.W. (1993) J. Urol. 150, 1564-1566. Bentveisen, F.M., George, F.W., McPhaul, M.J. and Wilson, J.D. (1994) Mol. Cell. Endocrinol. 105, 21-26.

Cooke, P.S., Young, P. and Cunha, G.R. (1991) Endocrinology 128, 2867-2873.

George, F.W. (1989) Endocrinology 124, 727-732.

Gonzales-Cadavid, N.F., Swerdloff, R.S., Lemmi, C.A.E. and Rajfer, J. (1991) Endocrinology 129, 1671-1678.

Griffin, J.E. and Wilson,' J.D. (1989) in The Metabolic Basis of Inherited Disease (Scriver, C.R., Beaudet, A.L., Sly, W.S. and Valle, D., eds.), 6th edn., pp. 1919-1944, MacGraw-Hill, New York.

Husmann, D.A. and McPhaul, M.J. (1991) Endocrinology 128, $383 \cdot 387$.
Husmann, D.A., Wilson, C.M., McPhaul, M.J., Tilley, W.D. and Wilson, J.D. (1990) Endocrinology 126, 259-2368.

Janssen, P.J., Brinkmann, A.O., Boersma, W.J. and van der Kwast, Th.H. (1994) J. Histochem. Cytochem. 42, 1169-1175.

Jung, I. and Baulieu, E.E. (1972) Nature (New Biol.) 237, 24-26.

Price, D. and Ortiz, E. (1965) in Organogenesis (Ursprung, R.L., de Haan, H., eds.), pp. 629-652, Holt, Rinehart and Wiston, New York.

Schultz, F.M. and Wilson, J.D. (1974) Endocrinology 94, 979-986.

Shannon, J.M. and Cunha, G.R. (1983) Prosiate 4, 367-373.

Takane, K.K., Husmann, D.A., McPhaul, M.J. and Wilson, J.D. (1991) Endocrinology 128, 2234-2238.

Takeda, H., Mizmo, T. and Lasnitzki, I. (1985) J. Endocrinol. 104, $87-92$.

Tizzano, E.F., Silver, M.M., Chitayat, D., Benichou, J.C. and Buch wald, M. (1994) Am. J. Pathol. 144, 906-914.

Tong, S.Y.C and Hutson, J.M. (1994) Program of the Annual Meeting of the Section on Urology, American Academy of Pediatrics, Dallas, TX, pp. 83-84 (Abstract 34).

Tsju, M., Shima, H., Terada, N. and Cunha, G.R. (1994) Endocrinology 134, 2198-2205.

Van der Schoot, P. (1992) J. Reprod. Fert. 95, 145-158.

Veyssiére, G., Berger, M., Jean-Faucher Ch., de Turckheim, M. and Jean, C. (1982) J. Steroid. Biochem. 17, 149-154.

Wasner, G., Hennerman, I. and Kratochwil, K. (1983) Endocrinology 113, 1771-1780.

Wilson, J.D., George, F.W. and Griffin, J.E. (1981) Science 211, 1278-1284.

Zegers, N.D., Claassen, E., Neelen, C., Mulder, E., van Laar, J.H., Voorhorst, M.M., Berrevoets, C.A., Brinkmann, A.O., van der Kwast, Th.H., de Winter, J.A.R., Trapman, J., Boersma, W.J.A (1991) Biochim. Biophys. Acta 1073, 23-32. 